\title{
Using Drawing As Intervention With Children For In-Service Preschool Teachers
}

I Ju (Crissa) Chen, ChaoYang University of Technology, Taiwan Chu Chih Liu, Kainan University, Taiwan

\begin{abstract}
This study provides a basic overview of in-service preschool teachers using drawing as intervention with children. Art therapy is used more often for the smaller children who have more difficulty to describe their emotions and feelings in recognizing words, such as anger, resentment, and different kind of abuses. As a matter of fact, the drawing has become a preferred mode of communication for them. The final result of this study is supporting the said theory. The best predictor of behavioral intention was the in-service teachers' attitudes while enrolling in the four-month non-credit course in Art Therapy and they believed that this would facilitate their future teaching by much more understanding the children's behaviors through non-verbal communication and actions. The perceived behavioral control was also the significant predictor of actual application behaviors. This study can provide a valuable reference for those in-service teachers who presently do not have any experience with art as an intervention with children.
\end{abstract}

Keywords: Behavioral Intention, Attitude, Subjective Norms, Perceived behavioral control, In-Service Preschool Teachers, the Theory of Planned Behavior

\section{INTRODUCTION}

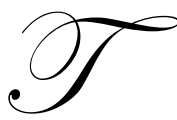

his study provides a basic overview to the in-service teachers of how to use children's drawings as intervention for better understanding of what problems the children are actually facing within their hidden subconscious or who are experiencing trauma or pain. Art therapy is used more often for the smaller children who have more difficulty describing their emotions and feelings in recognizing words, such as anger, resentment, and different kind of abuses. As a matter of fact, the drawing has become a preferred mode of communication for them. The theatrical application revealed in this study is related to a theory of planned behavior developed by Ajzen in 1985. The theory of planned behavior was used to predict the in-service teachers' intentions of working with children in art therapy. Three elements of the application proposed in this theory were investigated comprising the attitudes, norms, and perceived behavioral control, etc. The definition of "In-service teacher" used in this paper means the in-service preschool teachers who are considering enrolling in the four-month non-credit course in Art Therapy.

The Theory of Planned Behavior is the amendment and extension of Azjen $(1985,1991)$ and Fishbeins' (1980) 'The Theory of Reasoned Action (TRA)'. Other than two original factors in attitude toward the behavior and subjective social norm, TPB also includes perceived behavioral control. Ajzen's (2001) research shows that Perceived Behavioral Control will have an independent forecast result on both behavior intention and behavior, which explains why external control factors can affect in-service teachers' intentions of using drawing as intervention with children in preschool. Especially human behavior is influenced by behavioral, normative, and control beliefs.

Behavioral beliefs can bring forth an individual's attitude toward a behavior. Normative belief will bring about an individual's subject norm. Control belief will form the perceived behavioral control of an individual. Therefore, this article will investigate the in-service teachers' intentions of using drawing as intervention with children in preschool by using the related aspects of 'The Theory of Planned Behavior' (Figure 1). 


\section{Behavior intention (BI)}

Behavior intention means an individual's intention to perform a behavior. The intention can be learned from whether an individual is willing to try and how hard he or she will try to realize the behavior. TPB considers that behavior intention will directly influence an individual's decision on performing a specific behavior. If an individual cares for the behavior more, the subject norm will support his or her decision on performing such a behavior. Moreover, if perceived behavioral control toward the behavior is stronger, the inclination performing such behavior will be stronger.

\section{Attitude toward the behavior (AT)}

Attitude toward the behavior means an individual's evaluation of the behavior. Attitude toward behavior is often viewed as an individual's salient belief of such a behavior's outcome. It also means that the degree of importance in certain outcomes will affect an individual's behavior intention.

\section{Subject norm (SN)}

Subject norm means an individual's perception of social normative pressures that determines whether he or she should perform such behavior. An individual will decide whether he or she should accept other individuals' and groups' opinions and then take action.

\section{Perceived behavioral control (PBC)}

Perceived behavioral control means an individual perceives ease or difficulty of performing the particular behavior. It will reflect the past behavior of an individual and influence an individual's prediction of obstacles when performing such behavior. It also means opportunities and resources that an individual can control when performing the behavior, and affect his or her willingness in taking the action.

Above all, we can know the related aspects of The Theory of Planned Behavior. If the attitude, subject norm and perceived behavioral control are more positive and stronger, an individual's inclination to accomplish the behavior is more intensive.

No matter whether the researches are done overseas or domestically, the results all show that The Theory of Planned Behavior can make a contribution to explain or predict an individual's behavior intention. Thus, this article plans to conjecture in-service teachers' intentions of using drawing as intervention with children in the preschool by using The Theory of Planned Behavior.

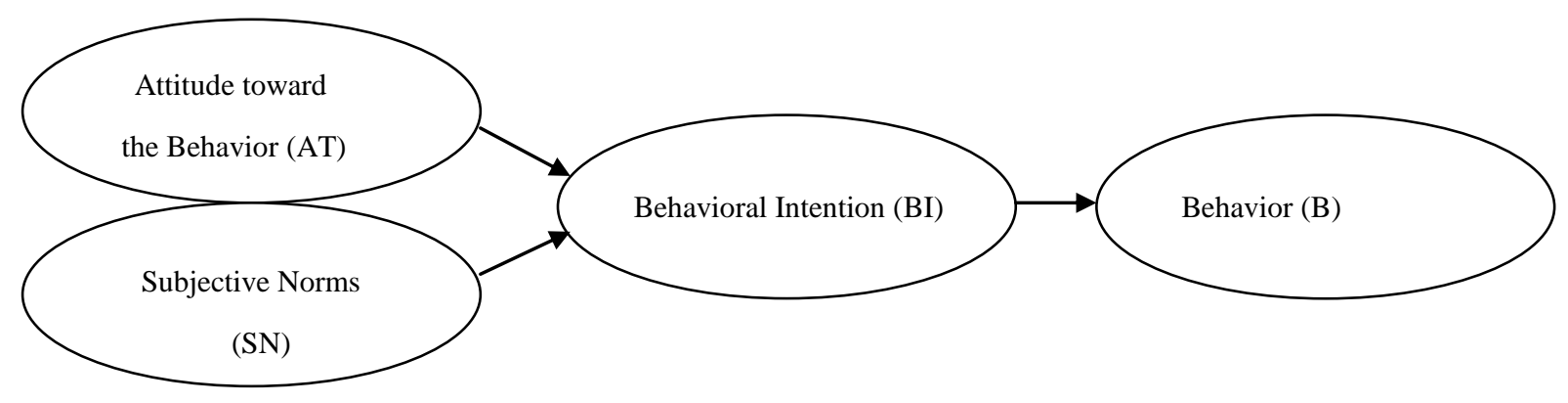

Figure 1: Theory of Reasoned Action (Ajzen and Fishbein, 1975)

\section{Social Cognitive Theory (SCT)}

Social Cognitive Theory, utilized in environment, person, and behavior, can explain an individual's behavior through the interaction of these three aspects. The theory considers that behavior happens in reciprocal determinism of an individual and environment. Through the interaction of these three aspects, an individual's behavior will be influenced by different situations. 
Bandura thinks that Social Cognitive Theory can perfectly explain human behavior in a dynamic environment, and take cognition, self-regulatory, and self-reflective processes as the major framework of cause and effect pattern. This theory believes that people initiate, regulate, and sustain their behavior by symbolizing, forethought, behavior modeling, self-regulating and self-reflecting (Bandura, 1988). Social Cognitive Theory includes many concepts, like past experiences, self-efficiency, and so forth. There are many researches prove that these concepts will pose a significant influence on individual's behavior and achievement.

Social Cognitive Theory (Bandura, 1986; 1988) points out that motivation and the exhibition of selfcontrol are made up from different self-regulation systems. One of the most important self-regulation systems is through self- efficiency. Self-efficiency means an individual's judgment on his or her capabilities in accomplishing particular work (Bandura, 1986), which also means the beliefs that are aggregated (Gist, 1987: 472-485; Shea \& Guzzo, 1987: 323-356; Spink, 1990: 301-311). Self- efficiency considers an individual's capability in realizing motivation, resource of cognition, and ability in controlling matters in an activity. At the same time, self- efficiency is a concept of many extents. It is deeply influenced by personal factor and environmental condition. By using the special structure of self-efficiency, we can predict individual's behavior more precisely. Moreover, through testing the size and intensity of self- efficiency, we can know the intensity of an individual's confidence.

Self- efficiency can also be defined as the belief in achieving special task and behavior (Gist, Schwoerer \& Rosen, 1989: 884-891; Stajkovic \& Luthans, 1998; Tracey, Hinkin, Tannenbaum \& Mathieu, 2001). This kind of learning efficiency comes from a good and extensive training process. Social Cognitive Theory points out that learning motivation comes from individuals, behavior, and environment, and it must take future, entire thoughts, and action into account (Bandura, 2001).

Bandura's Social Cognitive Theory has been extensively used in medication, policy-making management, human resources, computer skill training, and education fields. It is used as major theory basis of discussing human behavior in a dynamic environment (Bandura, 1977). Thus, this article utilizes two aspects of Social Cognitive Theory, which are environmental factor and personal factor, to understand whether these two factors will affect aboriginals' inclination to participate in career counseling.

In addition, the theory of planned behavior not only predicts but also provides a model for behavior modification. Apprising an individual his attitude towards the behavior, subjective norms and perceived behavioral control is supportive to his behavioral intentions to accomplish a given behavior. The theory of planned behavior supplied the theoretical model to more than 600 empirical studies of behavior prediction and changes in the past 20 years (Francis, et al, 2004). The theory of planned behavior has been adopted in the field of adult education in which professionals are being taught the use of a new method or interference.

\section{LITERATURE REVIEW}

Ajzen and Driver (1991) divided attitude into instrument attitude and affective attitude to predict the behavioral intention. The results showed that instrument attitude, affective attitude, subjective norms, and perceived behavior can predict behavioral intention. The results supported TPB. This study was appropriate to study the behavioral intention of teenagers to attend swimming training. The attitude, divided into instrument attitude and affective attitude can predict the behavioral intention more effectively.

Atsalakis and Sleap (1996) used TPB to investigate the behavioral intention to attend physical therapy in a month. In this study, 400 elementary school students' mothers were the population. The result showed that TPB can predict the behavioral intention to attend physical therapy effectively.

Theodorakis (1992) used TPB to investigate the intention to attend four weeks of swimming training. In this study, 98 children were the population and their ages were between 10-13 years old. The results showed that in TPB, subjective norms and perceived behavioral control can predict behavioral intention effectively.

Theodorakis (1994) used TPB as the main framework to study 395 female's intention to attend physical exercise for two months. Attitude toward the behavior and role were variables to predict the intention and behavior. In this study, 395 females were the population and their ages were between 18-45 years old. The results showed that perceived behavioral control affected the intention more than attitude toward the behavior and subjective norms. 
In 2000, Venkatesh, Morris and Ackerman used the theory of planned behavior to investigate whether an individual's decision-making process is influenced by gender differences. They compared men's and women's decision making processes. They found that men were more influenced by new technology and attitudes, while women were influenced by subjective norms and perceived behavioral control.

To sum up, from these results and a lot of other research using TPB methodology, we know that this theory can be used to predict individuals' behavior with a statistically valid degree of success. Therefore, we know that if we want to increase people's behavioral intentions or behavior, we need to understand their attitudes toward the behavior, the subjective norms, and their perceived behavioral control in order to predict why they are or are not going to do something. These reviews provided support to this research in studying in-service preschool teachers' behavioral intention to attend a four-month in-service teachers' art therapy course in teacher training program.

\section{METHOD}

\section{Participants/Setting}

The population for this study was randomly recruited in autumn 2008 from those who participated in a four-month in-service teachers' art therapy course in teacher training program. A total of 360 questionnaires were distributed to four randomly selected teacher training programs in the north, central, southern and eastern regions of Taiwan. At last, 312 valid questionnaires were collected in this study.

\section{Questionnaires/Materials}

In this study, firstly, the elicitation study was used as the research instrument following the recommendations of Francis (Francis, et al, 2004). Participants were asked to evaluate the advantages and disadvantages of their intentions to attend a four-month in-service teachers' art therapy course in teacher training program and describe they would approve or disapprove them, as well as to list the conditions that would make it easy and difficult if they acted according to the theory-driven statements. The goal of the elicitation study was to obtain groups of people's behavioral intentions in attitudes, norms, and perceived control regarding the statements based on the theory of planned behavior.

Secondly, questionnaires to measure behavioral intentions, attitudes toward the behavior, subjective norms, and perceived behavior control were developed according to the guidelines described by Francis (Francis, et al, 2004). Each questionnaire used the same theory-driven goal statements that were presented earlier as a reference. The first question was designed to inquire about the behavioral intentions of the students in teacher training education regarding the degree of which they were likely or unlikely to attend a four-month in-service teachers' art therapy course in teacher training program.

The second question was divided into two sub-questions. The first one inquired whether or not the participants believed that attending a four-month in-service teachers' art therapy course in teacher training program would increase their teaching ability (belief strength). The second part explored the strength of their attitudes toward the belief (or outcome evaluation).

The researcher designed the third question to ask the potential students about control behavior regarding the degree of which they were likely to attend a four-month in-service teachers' art therapy course in teacher training program. The intention scale included four items that described participants' gender, age, and teaching histories (e.g. who expressed a need for teach), in which respondents were asked to answer on a 7-point Likert scale.

\section{Procedure}

The null hypothesis stated that there is no relationship between in-service teachers' gender and attitudes toward the behavior, subjective norms, and perceived behavioral control. The sample of the population in this elicitation study $(n-30)$ consisted of potential in-service teachers in Taiwan who were considering attending teacher training program. The answers to the elicitation questions revealed the behavioral, normative, and control beliefs of the individuals who participated in this study. They were asked five open-ended questions, as Ajzen (1988) suggested, which elucidated underlying beliefs. 


\section{Statistical Analyses}

In this study, all the information was taken from the 7-point Likert scale questionnaire. It was analyzed based on the method developed by Fishbein and Ajzen (1980) and Ajzen (1985). As required by the theory, Pearson product-moment correlation coefficient was computed between pairs of the measured variables. However, the independent variables were behavioral beliefs multiplied by the outcome evaluation, normative beliefs multiplied by motivation to comply, and control beliefs multiplied by power of belief. To determine the relationship and weight on behavioral intentions of each indirect component, the researcher used multiple regressions to analyze the correlation coefficients of attitude toward the behavior, subjective norms, and perceived behavioral control on behavioral intentions independently.

This article uses Cronbach's $\alpha$ to understand children's drawings as intervention for better understanding in teaching. The items and the aspects of each item are coordinate. Based on the analysis and classification of this article, Cronbach's $\alpha$ is over 0.70 ; therefore, the reliability is high.

The related analysis of this article adopts Pearson's product-moment correlation. If teachers add more interest to the subject, the coefficient of one-tailed test will be higher. Thus, according to the analysis done by SPSS statistics software, the inclination of teacher to use the children's drawings as intervention for better understanding in teaching will be higher.

\section{RESULTS}

The effective questionnaires of this research are 312. After analyzing and classifying, we find out that subjects are mostly female teachers, which accounts for $87.8 \%$. The age of in-service teachers mostly range from 30 to 39 years old, which accounts for $46.3 \%$. The number of teachers who teach at private preschools are more than those at public preschools. Over $93.6 \%$ of in-service teachers teach drawing class for over five years. Most teachers have taken part in children drawing lectures or workshops in two years, which accounts for $9.3 \%$. On the other hand, according to the result of statistical analysis, nearly $90.5 \%$ of teachers do carry out using drawing as an intervention of children.

\section{Attitude}

Attitude has a direct and positive influence on behavior intention $\left(\beta=.52^{* *}, \mathrm{p}<.01\right)$. Consequently, this research infers that if teachers use children's drawing in teaching, then the expected resources will be more and the expected obstacle will be less. As a result, the intention of teachers to use children's drawing in teaching will be higher.

\section{Subject Norm}

Subject Norm does not have a negative and direct influence on behavior intention, according to Pearson's product-moment correlation one-tailed matrix influence $(\beta=-.01, p>.05)$. Thus, this research assumes that the social pressure that teachers endure has no significant influence on adapting children's drawings in their own teaching.

\section{Perceived Behavioral Control}

Perceived Behavioral Control poses a direct and positive influence on behavior intention $\left(\beta=.31^{* *}, p<.01\right)$. Therefore, this research assumes that when adapting children's drawing in teaching, if teachers' self-expectation of resources are more and obstacles are fewer, their behavior intention of adapting the method will be higher.

This research predicts the interpretability and pre- interpretability of teachers' intension to adopt children's drawings as intervention toward better understanding in teaching through The Theory of Planned Behavior. The result is that interpretabilities of attitude, subject norm, and perceived behavioral control toward behavior intention accounts for $47.5 \%$, which reaches a significant standard. In the meantime, the interpretabilities of attitude and perceived behavioral control toward behavior intention pose a direct and positive influence, and the effect sizes are 0.51 and 0.31 . The interpretabilities of perceived usefulness and perceived ease of use toward attitude reach a significant standard, which accounts for $61.6 \%$. At the same time, perceived usefulness and perceived ease of use 
will have indirect and positive influences on behavior intention through mediating of attitude. The indirect influences sizes are 0.31 and 0.11 . The interpretabilities of normative belief and conformity motivation toward subject norm reach a significant standard, which accounts for 58.4\%. Meanwhile, self-efficiency and facilitating condition will pose indirect influences on behavior intention through mediating of perceived behavioral control. The indirect influences sizes are 0.12 and 0.18 .

\section{DISSCUSSION}

It is easy to find that attitude will be influenced by teachers' perceived usefulness $\left(\beta=.27^{* *}\right)$ and perceived ease of use $\left(\beta=.62^{* *}\right)$. This means that teachers being conscious of adopting children's drawings as intervention for better understanding in teaching will benefit the teaching. If teachers take a positive attitude toward the method, then they will be more willing to adopt it. Therefore, when relevant agencies are promoting children's drawings as intervention for better understanding in teaching, they should value usefulness and ease of use so that quality and effectiveness of teaching can be improved.

From the result of this research, we find out that teachers' normative belief $(\beta=.06)$ does not have a significant influence on subject norm; therefore, it does not have an indirect influence on behavior intention, either. This means that teachers, will not be little influenced by other individuals or groups when teaching. Furthermore, the result shows that teachers of preschools have more independence than teachers of elementary and junior high schools; besides, the former will not be influenced by students, parents, colleagues, and authorities that much. On the other hand, conformity motivation $\left(\beta=.78^{* *}\right)$ has a direct significant influence on subject norm, and further affect behavior intention. If teachers have an important cognition of others or groups, they will agree to use children's drawings as intervention for better understanding in teaching. Hence, if teachers are more obedient, they will be more inclined to adopt children's drawings as intervention for better understanding in teaching. This research suggests that when promoting using drawing as intervention with children in teaching, we should not aspire after the external behavior of children's art therapy. On the contrary, we should let teachers realize the real meaning of adopting children's drawings as intervention for better understanding in teaching.

The result shows that teachers' self-efficiency $\left(\beta=.36^{* *}\right)$ and facilitating condition $\left(\beta=.57^{* *}\right)$ pose a significant influence on perceived behavioral control; consequently, there is no direct influence on behavior intention. This shows that when using drawing as intervention with children in teaching, if teachers' self-judgment of analyzing, exercising, and adapting drawings is higher, they will have more resources and fewer obstacles. As a result, teachers will have higher inclination to adapt children's drawings as intervention for better understanding in their owing teaching. From the above result, it is not difficult to find that the determinant of adapting using drawing as intervention with children in teaching is whether teachers have sufficient time and ability to perform such method. This research suggests that when promoting adapting children's drawings as intervention for better understanding in teaching, each school and relevant authorizes of governments should provide teachers with enough resources and equipment, and give teachers support and resources when adapting using drawing as intervention with children in teaching if needed.

\section{A STUDY OF MEANINGS OF MEDIATING: ATTITUDE, SUBJECT NORM, AND PERCEIVED BEHAVIORAL CONTROL}

The result of this research can be inferred that attitude's total variation accounts for $52 \%$, which is the highest percentage and the most important factor. However, attitude $\left(\mathrm{R}^{2}=.52 * *\right)$, subject norm $\left(\mathrm{R}^{2}=-.01\right)$, and perceived behavioral control $\left(\mathrm{R}^{2}=.31 * *\right)$ toward behavior intention can be interpreted by this total variation.

\section{CONCLUSION}

This research suggests that when promoting adapting children's drawings as intervention for better understanding in teaching, schools and relevant authorities of government should provide teachers with enough resources and equipment and give teachers support and resources when adapting children's drawings as intervention for a better understanding in teaching, if needed. Besides, we should try to understand teachers' preferences for adapting children's drawings as intervention for a better understanding in teaching and reinforce teachers' guidance to children's art accomplishments so that teachers can be more competent in putting the method into practice. 


\section{AUTHOR INFORMATION}

I Ju (Crissa) Chen is a bilingual person with very a strong education background. In her career she has pursued the opportunities to teach children, youths, adolescents and adults about the field of teacher education from both her educational and practical experiences. Presently, she is an assistant professor teaching in a college-level teacher education, adult education and early childhood education. With an appreciation of her academic background, combined with multicultural teaching experiences and counseling concentration, she looks forward to becoming an effective researcher.

\section{REFERENCES}

1. Ajzen, I. (1985). From intention to actions: A theory of planned Behavior In Kuhl, J. \& Beckmann, J. (eds.), Action control: Form cognition to behavior (pp. 11-39), Berlin Heidelberg SpringerVerlag.

2. Ajzen, I. (1991). The theory of planned behavior. Organizational Behavior and Human Decision Processes, 50, 179-211.

3. Ajzen, I. (2001). Constructing a TPB questionnaire: Conceptual and methodological considerations. Retrieved October 16, 2003, from University of Massachusetts, Office of Information Technologies Web Site: http://www-unix.oit.umass.edu/ aizen/

4. Ajzen, I. (2002a). Perceived behavioral control, self-efficacy, locus of control, and the theory of planned behavior. Journal of Applied Social Psychology, 32, 1-20.

5. Ajzen, I., \& Driver, B. L. (1991). Application of the theory of planned behavior to leisure choice. Journal of Leisure Research, 24, 207-224.

6. Ajzen, I. \& Fishbein, I. (1975). Belief, attitude, intention and behavior: An introduction to theory and research. Reading, MA: Addison-Wesley.

7. Atsalakis and M. Sleap (1996). Registration of children in a physical activity program: an application of the theory of planned behavior, Pediatric Exercise Science 8, pp. 166-176.

8. $\quad$ Bandura, A. (1977). Social Learning Theory. Englewook Cliffs, NJ: Prentice Hall.

9. Bandura, A. (1986). Social Foundations of Thought and Action: A Social Cognitive Theory. Englewood, Cliffs NJ: Prentice-Hall.

10. Bandura, A. (1988). Social Learning Theory, Englewood Cliffs. NJ : Prentice Hall.

11. Bandura, A. (2001). Social cognitive theory: An agentic perspective, Annual Review of psychology, 52: $1-26$.

12. Francis, J.J, Eccles MP, Johnston M, et al: Constructing Questionnaires Based Upon the Theory of Planned Behavior. Newcastle Upon Tyne, United Kingdom, ReBECI, 2004

13. Gist, M. E. (1987). Self-Efficacy: Implications for Organizational Behavior and Resource Management. Academy of Management Review, 12(3): 472-485.

14. Gist, M. E., Schwoerer, C. E., \& Roson, B. (1989). Effects of alternative training methods on self-effecy and performance in computer software training, Journal of applied psychology, 174: 884-891.

15. Norris, A.E. \& Ford, K. (1995). Condom use by low-income African American and Hispanic youth with a well-known partner: Integrating the health belief model, theory of reasoned action, and the construct accessibility model. Journal of Applied Social Psychology, 25, 1801-1830.

16. Shea, G. P., \& Guzzo, R. A. (1987). Groups as Human Resources. Personnel and Human Resources Management, 5: 323-356.

17. Spink, K. S. (1990).Group Cohesion and Collective Efficacy of Volleyball Teams, Journal of Sport and Exercise Psychology. 12: 301-311

18. Stajkovic, A. D. \& Luthans, F. (1998). Self-efficacy and work-related performance: A meta-analysis. Psychological Bulletin, 124, 240-261.

19. Theodorakis, Y. (1992). Prediction of athletic participation: A test of planned behavior. Perceptual of and the prediction of exercise behavior. Perceptual and Motor Skills, 74(2), 371-379.

20. Theodorakis, Y. (1994). Prediction of athletic participation: A test of planned behavior. Perceptual of and the prediction of exercise behavior. Sport Psychologist, 8, 149-165.

21. Tracey, J.B., Hinkin, T.R., Tannenbaum, S.I., Mathieu, J.E. (2001) The influence of individual characteristics and the work environment on varying levels of training outcomes, Human Resource Development Quarterly, 12(1):5-22.

22. Venkatesh, V., Morris, M. G., \& Ackerman, P. L. (2000). A longitudinal field investigation of gender difference in individual technology adoption decision making process. Organizational Behavior and Human Decision Process, 83(1), 33-60. 
NOTES 